\title{
MicroscopyPioneers
}

\section{Pioneers in Optics: Edmund Hartnack and Jean-Baptiste Romé de l'Isle}

\section{Eric Clark}

From the website Molecular Expressions created by the late Michael Davidson and now maintained by Eric Clark, National Magnetic Field Laboratory, Florida State University, Tallahassee, FL 32306

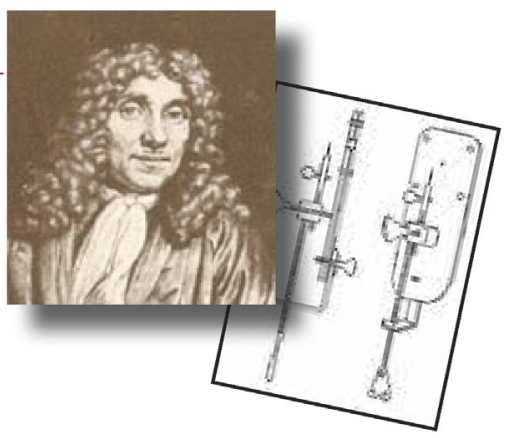

eclark@magnet.fsu.edu

\section{Edmund Hartnack (1826-1891)}

Edmund Hartnack was a nineteenth-century German microscope maker who studied his craft in Berlin under Wilhelm Hirschmann. Few details about his life are known, but many fine examples of his work remain. In 1857, Hartnack joined the instrumentmaking firm of his uncle, Georges Oberhauser (1798-1868), which was based in Paris and enjoyed a reputation for high-quality products. In 1860, Hartnack was given full control of the firm, which began trading under his name. Due to the onset of the French-

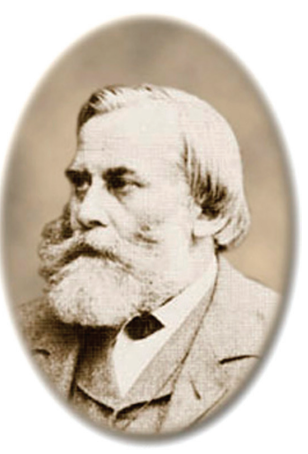
German war, Hartnack left France in 1870 and returned to Germany, settling in Potsdam. The Parisian branch of Hartnack's business was run for a time by his partner, Adam Prazmowski, but was eventually absorbed by the Nachet instrument company.

Hartnack was considered a practical optician and is credited with several advances in the field. For instance, he reportedly made improvements to the drum-shaped microscope that allowed for better and more easily obtained oblique lighting. He was also one of the first instrument makers to include a substage condenser in his designs. Hartnack is perhaps best known, however, for the great improvements he made to water immersion lenses. This type of lens had been explored for practical use by both Sir David Brewster and Giovanni Amici, but only with partial success. One of the main problems with the earlier water immersion lenses apparently was their lack of a correction collar, a flaw that meant they could only obtain good spherical aberration correction when they were used in conjunction with a cover glass of a very exact thickness. When Hartnack combined the water immersion principle, however, with a correction collar, the image quality obtained with the lenses improved to such an extent that they were highly marketable. Hartnack began selling water immersion lenses fitted with correction collars around 1859, and they were very popular among Parisian researchers.

\section{Jean-Baptiste Romé de I'Isle (1736-1790)}

Jean-Baptiste Romé de l'Isle was a French mineralogist who is best known as one of the founders of optical crystallography. He was born on August 26, 1736, in Gray, France. Little is known about his early life, but he was a member of the military and acted as an officer in the East Indies. Romé de l'Isle was captured by the English in 1761 and remained their prisoner for three years.

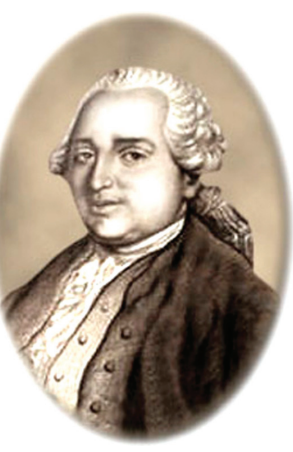

When Romé de l'Isle returned to France in 1764, he developed an interest in chemistry, followed by a passion for mineralogy. He cataloged several private collections and carried out a significant amount of research. Subsequent to years of careful measurements and crystal observations, he published Essal de Cristallographic in 1772. A second edition of the work, which is regarded as his major contribution, was published in three volumes as Cristallographie in 1783.

Within his works, Romé de l'Isle established that various shapes of crystals of the same natural or artificial substance are all closely related to each other. Measurements he took with a goniometer enabled him to determine that the angles between corresponding faces of a crystal are always the same, which is often described as the first law of crystallography. In addition, he demonstrated that these angles are a characteristic of mineral type, introduced the concept of truncation, and also enlarged the crystallographic vocabulary.

Romé de l'Isle died in Paris on March 7, 1790. However, through his remarkable efforts and those of other renowned eighteenth-century researchers, crystallography was elevated from a minor field of interest into a prominent science. 


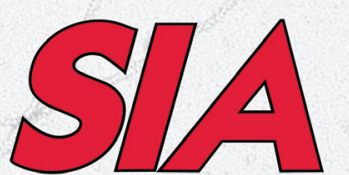

1 TO 50 MEGAPIXELS live and slow scan

MAGNIFICATION FACTOR OF 1 on bottom mounted cameras

DifFRACTION BEAM STOP on side mounted cameras
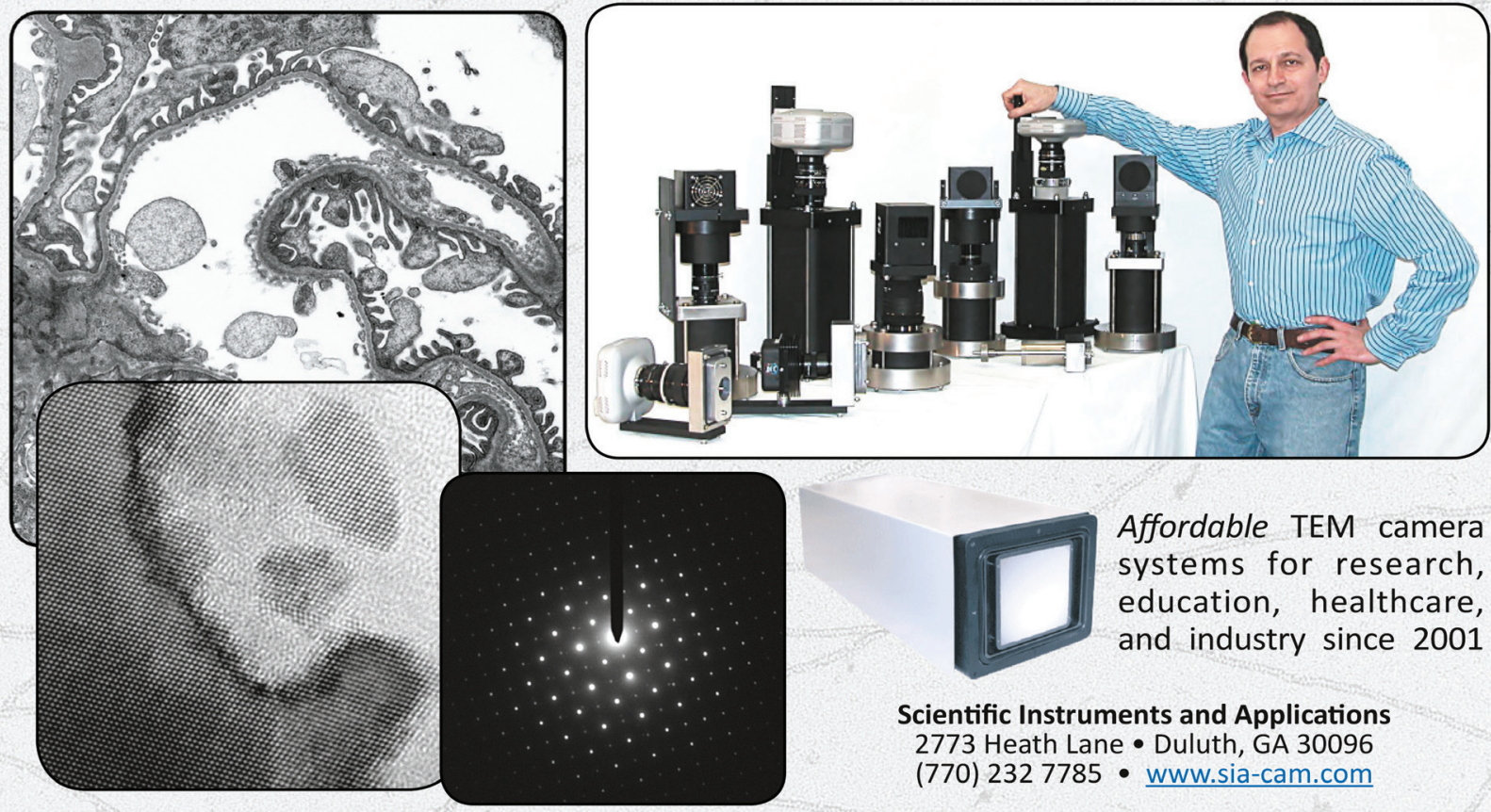

Affordable TEM camera systems for research, education, healthcare, and industry since 2001

Scientific Instruments and Applications

2773 Heath Lane • Duluth, GA 30096

(770) $2327785 \cdot$ www.sia-cam.com

\section{Refurbishing or servicing an} electron microscope? Scope us out for your ion pump needs.

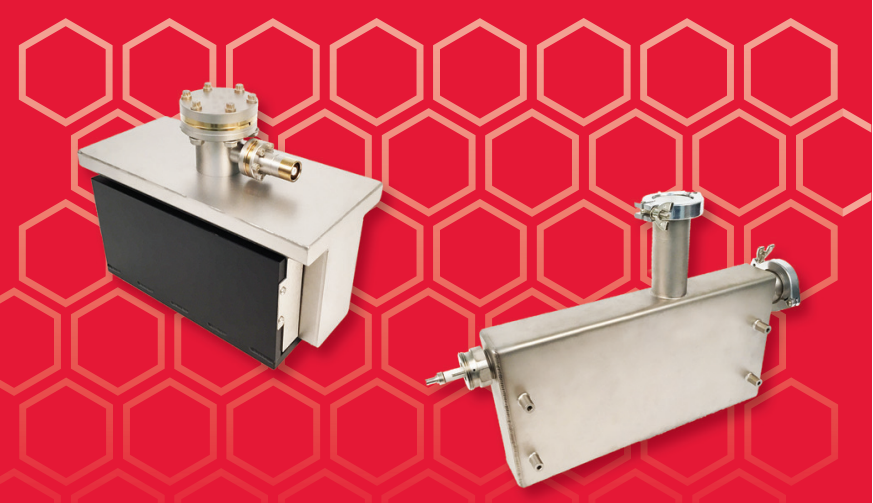

New | Rebuilt | Rebuilding Services

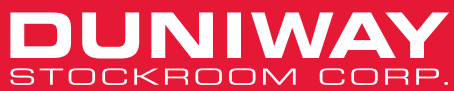

800.446 .8811

\section{MINITOOL \\ Precision Micro-Tools}

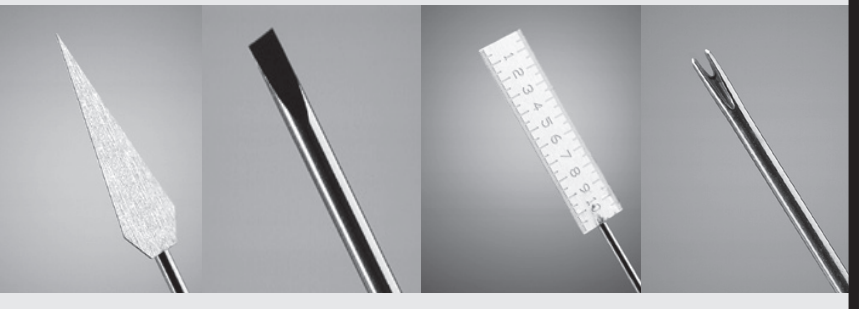

Efficient, precise and realistically proportioned instruments are ideal for microscopists. Our line of micro-tools includes needles, gravers, chisels, knives, hooks and mirrors, probes, spatulas, scribes and microrulers.

All 32 tools are offered singly or in sets of eight tools with handles. Available in tip diameters from $.025 \mathrm{~mm}$ to $1.00 \mathrm{~mm}$.

\section{www.minitoolinc.com} info@minitoolinc.com 


\section{Erase black squares with Evactron ${ }^{\circledR}$ plasma cleaning}

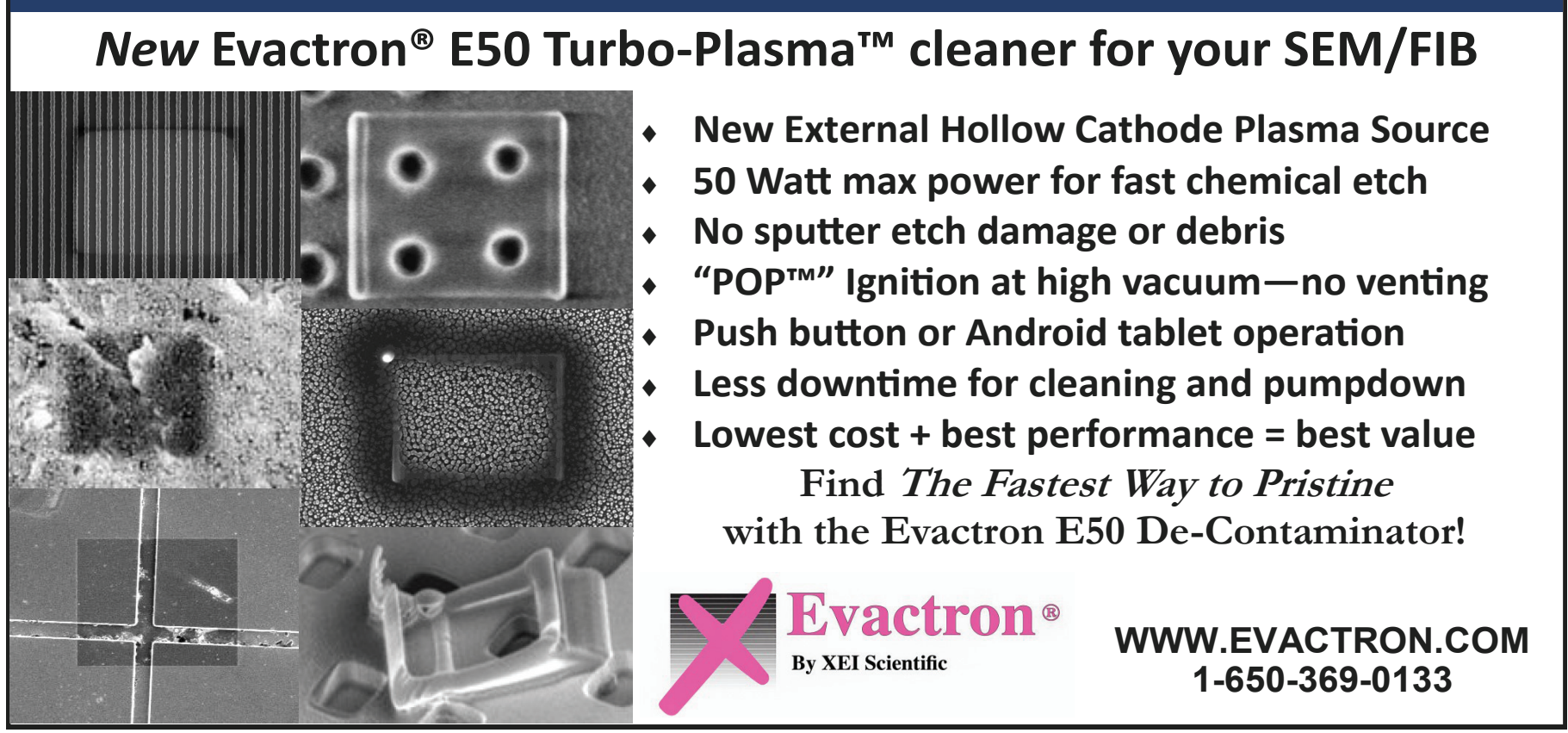

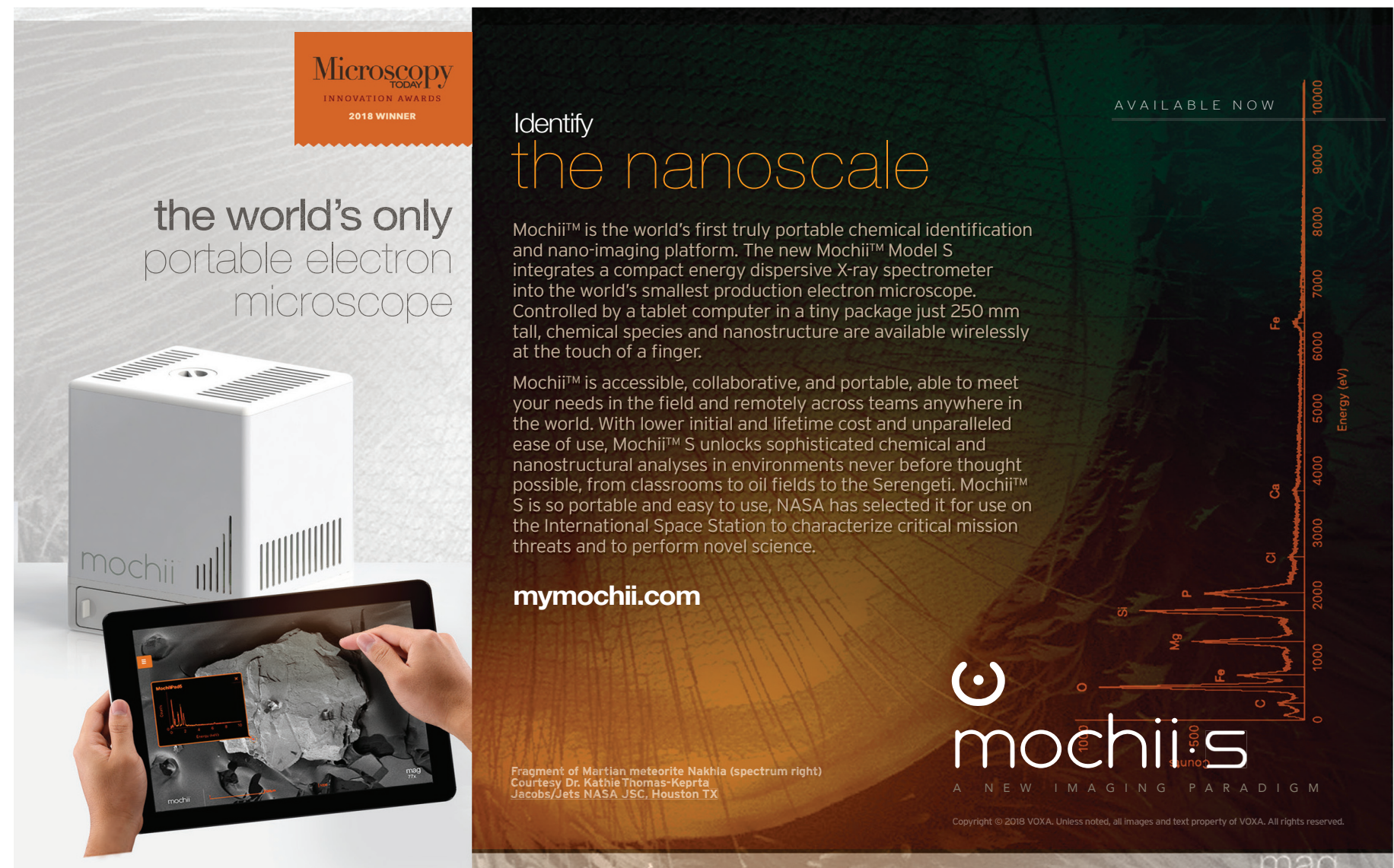

